\title{
A Factor Analytic Approach to Symptom Patterns in Dementia
}

\author{
Lars Gustafson, ${ }^{1}$ Catarina Erikson, ${ }^{1}$ Siegbert Warkentin,, ${ }^{1}$ Arne Brun, ${ }^{2}$ \\ Elisabet Englund, ${ }^{2}$ and Ulla Passant ${ }^{1}$ \\ ${ }^{1}$ Department of Geriatric Psychiatry, Clinical Sciences, Lund, Lund University, 22185 Lund, Sweden \\ ${ }^{2}$ Department of Pathology, Clinical Sciences, Lund, Lund University, 22185 Lund, Sweden
}

Correspondence should be addressed to Lars Gustafson, lars.gustafson@med.lu.se

Received 25 August 2010; Revised 9 November 2010; Accepted 10 December 2010

Academic Editor: Christiane Reitz

Copyright (C) 2011 Lars Gustafson et al. This is an open access article distributed under the Creative Commons Attribution License, which permits unrestricted use, distribution, and reproduction in any medium, provided the original work is properly cited.

\begin{abstract}
Previous publications have shown a high diagnostic sensitivity and specificity of three short clinical rating scales for Alzheimer's disease (AD), frontotemporal dementia (FTD), and vascular dementia (VaD) validated against neuropathological (NP) diagnoses. In this study, the aim was to perform an exploratory factor analysis of the items in these clinical rating scales. The study included 190 patients with postmortem diagnoses of $\mathrm{AD}(n=74), \mathrm{VaD}(n=33)$, mixed $\mathrm{AD} / \mathrm{VaD}(n=31)$, or FTD $(n=52)$. The factor analysis produced three strong factors. Factor 1 contained items describing cerebrovascular disease, similar to the Hachinski Ischemic Score. Factor 2 enclosed major clinical characteristics of FTD, and factor 3 showed a striking similarity to the AD scale. A fourth symptom cluster was described by perception and expression of emotions. The factor analyses strongly support the construct validity of the diagnostic rating scales.
\end{abstract}

\section{Introduction}

Dementia is a clinical syndrome with a marked variety of aetiology, clinical profile, severity, and clinical course. The differential diagnosis between various clinical and aetiological subtypes may be difficult, and so far no single diagnostic approach or biomarker has fully solved these problems. Few clinical symptoms and signs are pathognomonic of dementia or a specific type of dementia. It is mostly the symptom constellation, the timing of appearance, and the clinical progression that lead to a diagnostic conclusion [1]. A positive diagnosis of dementia is often made comparatively late in the disease process and for this reason most clinical investigations are performed on patients in an advanced stage or retrospectively on patients with organic dementia defined postmortem.

Relevant to the present study, most factor analyses of symptoms in dementia have been carried out for descriptive purposes and less for the construction of diagnostic rating scales. A conventional factor analysis of 78 symptoms in early onset dementia resulted in 14 clinically meaningful factors [2]. Three factors contained symptoms of severe dementia, three factors described mood changes or delusions, five factors described personality changes and impaired control of emotional expressions, and three factors described various motoric dysfunctions. The factors showed specific relationships with regional Cerebral Blood Flow (rCBF) and psychometric testing $[2,3]$. In another study, factor analysis of 16 symptoms of the Brief Psychiatric Rating Scale (BPRS) in 87 geropsychiatric patients resulted in five clinical dimensions: withdrawn depression, agitation, cognitive dysfunction, hostile suspiciousness, and psychotic distortion [4]. Petrovic et al. [5] identified four symptom clusters based on factor analysis of the Neuropsychiatric Inventory (NPI) in patients with dementia: psychosis, psychomotor, mood liability, and instinctual factors. Another factor analysis of ten NPI items in probable AD resulted in three subsyndromes: mood, psychotic, and frontal [6], and a factor analysis of the 12 item NPI showed the presence of four behavioural subsyndromes called hyperactivity, psychosis, affective symptoms, and apathy [7]. Thus, so far few factor analytic studies of dementia symptoms have focused on differential diagnostic issues. Björkelund et al. presented a systematic review of 30 studies of the Organic Brain Syndrome (OBS) scale for description of delirium and dementia [8]. Factor analysis of the 53 clinical items of the OBS scale revealed three factors 
describing different types of disorientation and nine factors describing different cognitive and emotional disturbances, and neurological symptoms.

Our previous publications from the Lund Longitudinal Dementia Study have introduced two short diagnostic rating scales, one for recognition of Alzheimer's disease $(\mathrm{AD})$, the $\mathrm{AD}$ scale, and the other for diagnosis of primary degenerative frontotemporal dementia (FTD), the FTD scale [9]. Differential diagnostic screening with these two rating scales and the Hachinski Ischemic Score (HIS) scale [10] has been evaluated against postmortem neuropathological (NP) diagnoses to analyze their feasibility for antemortem clinical diagnosis of $\mathrm{AD}$, vascular dementia $(\mathrm{VaD})$, mixed $\mathrm{AD} / \mathrm{VaD}$, and FTD [11]. The sensitivity and specificity of the AD scale were 0.80 and 0.87 , respectively, of the FTD scale 0.93 and 0.92 , respectively, and of the HIS score (VaD diagnosis) 0.69 and 0.92 , respectively. Cases with mixed $\mathrm{AD} / \mathrm{VaD}$ generally presented a combination of high $\mathrm{AD}$ and ischemic scores [11]. However, no analysis of the individual items was performed. Therefore, we present results from a principal component factor analysis of the individual items of the AD, FTD, and HIS scales (Table 5). The factor analyses were used to identify clinical dimensions of dementia and to confirm the construct validity of the clinical rating scales. Furthermore, the relationship between different items and $\mathrm{NP}$ diagnoses was studied as also the possibility to modify and improve the clinical rating scales as diagnostic tools.

\section{Material and Methods}

This study was based on a prospective longitudinal clinical work-up with a final postmortem NP examination. The study covers the time period from the late 1960s and onwards and includes consecutive patients with symptoms of dementia referred to the Psychogeriatric and Psychiatric Departments of the University Hospital in Lund. The patients and other informants were interviewed and the neuropsychiatric symptoms and signs of the HIS, $\mathrm{AD}$, and FTD scales were evaluated and scored by a psychiatrist with experience in the dementia field. The 30 items and scores of the three rating scales are presented in (Table 5). Exclusion criteria were chronic psychosis and epilepsy, severe somatic disease, severe head trauma, addiction, stroke with remaining gross focal neurological symptoms, and conditions that did not allow the application of the three clinical rating scales. All patients fulfilled DSM III and ICD-10 criteria for a dementia syndrome $[12,13]$. The NP diagnoses were based on standardized NP procedures and criteria recently published [11]. The age characteristics and NP diagnoses are shown in Table 1. The factor analytic study was based on 190 cases (77 male and 113 female) deceased in the years 1967-2007 with an NP diagnosis of AD, FTD, VaD, or mixed $\mathrm{AD} / \mathrm{VaD}$ and with a complete diagnostic scoring. Patients with other NP diagnoses or incomplete scoring were not included.

The average age at onset in the total material was 64.6 \pm 12.3 years (range 30-92 years) and differed significantly between all the four major NP groups (ANOVA followed by Student-Newman-Keuls test, Table 1). The mean age at death was $73.6 \pm 11.35$ years (range $34-97$ years) with significant group differences, except between $\mathrm{AD}$ and $\mathrm{VaD}$ (74.7 and 76.5 years, resp.). The mean duration of illness was $8.9 \pm 5.3$ years (range 1-26 years). The mean duration was similar in the AD and FTD groups (10.4 and 9.1 years, resp.). Only AD corresponded with a significantly longer duration compared with $\mathrm{VaD}$ and mixed $\mathrm{AD} / \mathrm{VaD}$.

2.1. Diagnostic Rating Scales. The three diagnostic rating scales, HIS scale, AD scale, and FTD scale, and their thirty clinical items (Table 5) have been presented in a previous publication as also the validation of the three diagnostic scores against NP diagnoses [11]. The 30 items were selected for the purpose of differential diagnosis of dementia diseases. In this paper, the factor analysis was performed of the diagnostic items scored in the 190 patients with NP diagnoses.

2.2. Factor Analytic Approach. In order to detect clusters of clinical symptoms and signs, the item scores were subjected to conventional factor analysis using the principal component method with varimax rotation [14]. Factor analysis is a construct validity tool aiming at identifying underlying clinical dimensions. The validity of a symptom cluster has been defined as the common variance of the factor and the construct validity is studied by comparison with other constructs [15]. Factors with an eigenvalue exceeding 1.0 and an interpretable constellation of items are usually considered of interest for the clinical description. The factor structure will be described by the symptoms with factor loadings in the rotated factor matrix, which are considered as "significant" (at the $1 \%$ level), although there is no accepted standard error of factor loadings [16]. Factor loadings of 0.30 or greater are judged as significant in most textbooks [17-19]. The simple structure idea is further corroborated by a pattern of zero factor loadings [20]. There are different opinions in terms of sample size in factor analysis. Hatcher [21] recommended that the number of subjects should be five times the number of variables, (which in this study means 150 ) or at least 100, while Hutcheson and Sofroniou [22] recommended 150-300 subjects.

2.3. Statistical Analysis. Factor analysis was performed with Stat View version 5.0.1. SAS Institute Inc. We performed a principal component analysis of the 30 items included in the rating scales, using an orthotran varimax procedure. Factors with eigenvalues greater than 1.9 were selected in the three-factor solution. Factor loadings with higher values (i.e., minimum 0.25 ) were included when they contributed to a clinically meaningful interpretation pattern.

\section{Results}

There was a marked variation of the prevalence of diagnostic scale items for the NP groups (Table 2).

Factor analysis of the 30 items scored in the 190 patients resulted in several factors with eigenvalues exceeding 1.0. We will first present the three-factor solution with eigenvalues of 5.2, 3.7, and 1.9 (Table 3). All three factors were clearly 
TABLE 1: Age at onset, age at death, duration of illness (mean \pm SD (range)), and gender characteristics in 190 patients with neuropathological dementia diagnosis.

(a)

\begin{tabular}{|c|c|c|c|c|c|}
\hline NP diagnosis & $n(\%)$ & Male/Female & $\begin{array}{l}\text { Age at onset } \\
\text { (years) }\end{array}$ & $\begin{array}{l}\text { Age at death } \\
\text { (years) }\end{array}$ & $\begin{array}{c}\text { Duration of illness } \\
\text { (years) }\end{array}$ \\
\hline $\mathrm{AD}$ & $74(35.4)$ & $20 / 54$ & $\begin{array}{c}64.2 \pm 10.2 \\
(44-88)\end{array}$ & $\begin{array}{c}74.7 \pm 8.7 \\
(59-93)\end{array}$ & $\begin{array}{c}10.4 \pm 4.9 \\
(1-21)\end{array}$ \\
\hline FTD & $52(24.9)$ & $23 / 29$ & $\begin{array}{c}54.7 \pm 10.9 \\
(30-84)\end{array}$ & $\begin{array}{c}63.8 \pm 11.5 \\
(34-85)\end{array}$ & $\begin{array}{c}9.1 \pm 5.2 \\
(1-26)\end{array}$ \\
\hline $\mathrm{VaD}$ & $33(15.8)$ & $19 / 14$ & $\begin{array}{c}69.5 \pm 9.9 \\
(53-89)\end{array}$ & $\begin{array}{c}76.5 \pm 9.0 \\
(58-93)\end{array}$ & $\begin{array}{c}7.1 \pm 6.4 \\
(1-26)\end{array}$ \\
\hline Mixed AD/VaD & $31(14.8)$ & $15 / 16$ & $\begin{array}{c}77.0 \pm 6.5 \\
(64-92) \\
\end{array}$ & $\begin{array}{c}84.3 \pm 6.3 \\
(71-97) \\
\end{array}$ & $\begin{array}{c}7.4 \pm 4.0 \\
(1-15) \\
\end{array}$ \\
\hline Total & $190(100)$ & $77 / 113$ & $\begin{array}{c}64.6 \pm 12.3 \\
(30-92)\end{array}$ & $\begin{array}{c}73.6 \pm 11.5 \\
(34-97)\end{array}$ & $\begin{array}{c}8.9 \pm 5.3 \\
(1-26)\end{array}$ \\
\hline
\end{tabular}

(b)

\begin{tabular}{lccc}
\hline Group comparisons (difference $(95 \%$ CI) $)$ & Age at onset & Age at death ${ }^{\# \#}$ & Duration of illness $^{\# \# \#}$ \\
\hline AD versus FTD & $9.5(5.7-13.3)^{*}$ & $10.9(7.3-14.4)^{*}$ & $1.3(-0.5-3.1)$ \\
AD versus VaD & $-5.2(-9.5--1.0)^{*}$ & $-1.8(-5.5-1.8)$ & $3.3(1.0-5.6)^{*}$ \\
AD versus mixed AD/VAD & $-12.7(-16.7--8.8)^{*}$ & $-9.6(-13.1--6.2)^{*}$ & $2.9(1.0-4.9)^{*}$ \\
FTD versus VaD & $-14.7(-19.4--10.1)^{*}$ & $-12.7(-17.4--8.0)^{*}$ & $2.0(-0.5-4.5)$ \\
FTD versus mixed AD/VaD & $-22.2(-26.5--17.9)^{*}$ & $-20.5(-25.0--16.1)^{*}$ & $1.7(-0.5-3.8)$ \\
VaD versus mixed AD/VaD & $-7.5(-11.7--3.3)^{*}$ & $-7.8(-11.7--3.9)^{*}$ & $-0.4(-3.0-2.3)$ \\
\hline
\end{tabular}

${ }^{\#}$ ANOVA F $3,184=36(P<.001)$

\#\#ANOVA F $3,186=34(P<.001)$

\#\#\#ANOVA $\mathrm{F}_{3,184}=4(P<.007)$

${ }^{*}$ Significant difference $(P<.05)$ Student-Newman-Keuls test.

interpretable and clinically relevant with several items with strong factor loadings explaining $35.9 \%$ of the total variance. The majority of items were unique, that is, mainly correlating to a single factor.

3.1. The Three-Factor Solution. The first and strongest factor was comprised of eight items with positive factor loadings (0.47-0.75): "history of stroke", "stepwise progression", "focal neurological symptoms", "abrupt onset", "focal neurological signs", "evidence of associated arteriosclerosis", "history of hypertension", and "fluctuating course". Furthermore, there was one item, "slow progression" with a high negative factor loading $(-0.81)$ and four items with moderately negative factor loadings $(-0.25$ to -0.43$)$ : "dyspraxia, dysphasia, and dysgnosia", "early loss of insight", "early spatial disorientation", and "early amnesia for remote events". Thus factor 1 in several aspects agreed with the structure and scoring of the HIS scale with the exception of "relative preservation of personality" and "nocturnal confusion".

Factor 2 (Table 3) included eight items with positive factor loadings (0.26-0.67): "echolalia, late mutism, amimia", "early signs of disinhibition", "early loss of insight", "progressive reduction of speech", "Klüver-Bucy syndrome", "stereotypy of speech", "logorrhoea", and "irritability, dysphoria", all of them present in the FTD scale. Four items showed negative factor loadings: "relative preservation of personality" (-0.47), "dyspraxia, dysphasia, dysgnosia" (-0.58), "early spatial disorientation" (-0.72), and "early amnesia for remote events" $(-0.67)$. Thus the structure of the second factor agrees with the symptom pattern described in the original FTD scale with the exception of "confabulation".

Finally, factor 3 (Table 3) contains eleven items with positive factor loadings (0.27-0.63): "dyspraxia, dysphasia, dysgnosia," "epileptic seizures of late onset," "increased muscular tension," "myoclonic twitchings," "early spatial disorientation," "early amnesia for remote events," "confabulation," "logoclonia," "nocturnal confusion," "irritability, dysphoria," and "emotional incontinence". Seven of these items belong to the $\mathrm{AD}$ scale. However, two other items, "irritability-dysphoria" and "confabulation", belong to the FTD scale, and the two items "nocturnal confusion" and "emotional incontinence" belong to the HIS scale. There was no clinical item with an important negative factor loading in factor 3 .

The three-factor solution based on the clinical scoring of 190 patients with NP diagnosis of $\mathrm{AD}, \mathrm{VaD}$, mixed $\mathrm{AD} / \mathrm{VaD}$, and FTD showed striking similarities to the three previously established short clinical rating scales. Only two of the 30 items, "depression" and "somatic complaints", did not show any factor loading above 0.25 or below -0.25 . 
TABLe 2: Prevalence of clinical items (in percent) in four neuropathologically diagnosed dementia groups, $\operatorname{AD}(n=74)$, FTD $(n=52)$, $\operatorname{VaD}(n=33)$, and mixed $\mathrm{AD} / \mathrm{VaD}(n=31)$.

\begin{tabular}{|c|c|c|c|c|}
\hline & $\mathrm{AD}$ & FTD & $\mathrm{VaD}$ & Mixed $\mathrm{AD} / \mathrm{VaD}$ \\
\hline Slow progression & 96 & 92 & 24 & 76 \\
\hline Early loss of insight & 43 & 75 & 15 & 41 \\
\hline Early amnesia for remote events & 77 & 8 & 15 & 66 \\
\hline Early spatial disorientation & 77 & 2 & 21 & 72 \\
\hline Dyspraxia, dysphasia, dysgnosia (all symptoms present to some extent) & 84 & 10 & 35 & 66 \\
\hline Logoclonia (stuttering-like speech disturbance) & 14 & 2 & 0 & 7 \\
\hline Logorrhea (voluble speech) & 8 & 15 & 0 & 7 \\
\hline Progressive reduction of speech & 42 & 79 & 56 & 21 \\
\hline Epileptic seizure of late onset & 23 & 6 & 12 & 17 \\
\hline Increased muscular tension & 57 & 17 & 35 & 24 \\
\hline Myoclonic twitchings & 19 & 0 & 0 & 14 \\
\hline Klüver-Bucy syndrome (hyperorality, hypersexuality, utilization behaviour) & 8 & 37 & 9 & 4 \\
\hline Early signs of disinhibition & 16 & 79 & 24 & 10 \\
\hline Irritability, dysphoria & 37 & 52 & 35 & 41 \\
\hline Confabulation, spontaneous & 32 & 14 & 24 & 31 \\
\hline Stereotypy of speech & 3 & 25 & 0 & 0 \\
\hline Echolalia, late mutism, amimia (during the course) & 10 & 56 & 3 & 0 \\
\hline Abrupt onset & 10 & 2 & 74 & 21 \\
\hline Stepwise progression & 4 & 6 & 74 & 38 \\
\hline Fluctuating course & 27 & 6 & 79 & 66 \\
\hline Nocturnal confusion & 26 & 4 & 15 & 28 \\
\hline Relative preservation of personality & 41 & 2 & 62 & 28 \\
\hline Depression & 18 & 37 & 44 & 14 \\
\hline Somatic complaints & 27 & 31 & 47 & 31 \\
\hline Emotional incontinence & 32 & 19 & 47 & 10 \\
\hline History of hypertension & 15 & 8 & 65 & 31 \\
\hline History of stroke & 12 & 4 & 77 & 45 \\
\hline Evidence of associated atherosclerosis & 18 & 10 & 62 & 41 \\
\hline Focal neurological symptoms & 10 & 14 & 74 & 31 \\
\hline Focal neurological signs & 15 & 10 & 56 & 41 \\
\hline
\end{tabular}

3.2. The Four-Factor Solution. To test the possibility of additional clinical dimensions for the description and classification of dementia, a four-factor solution was also calculated. This resulted in four strong factors with eigenvalues $5.2,3.7,1.9$, and 1.6 , accounting for $41.2 \%$ of the unrotated and rotated clinical variance. Positive factor loadings greater than 0.25 corresponding to $P<.01$ are shown in Table 4 .
There were strong similarities between the first three factors of the four-factor solution and the factors of the threefactor solution. All four factors were interpretable as clinically meaningful. The new fourth factor described an interesting clinical dimension including five rather unique items with positive factor loadings, "depression" (0.72), "somatic complaints" (0.55), "emotional incontinence" (0.42), "irritability, dysphoria" (0.40), and "progressive reduction of 
TABLE 3: A Three-factor analysis of 30 clinical items scored in 190 patients with a neuropathological diagnosis of AD, FTD, VaD, and mixed $\mathrm{AD} / \mathrm{VaD}$. Factor loadings $\geq+0.25$ are in bold. Factor loadings $\leq-0.25$ are set in italic.

\begin{tabular}{|c|c|c|c|}
\hline & Factor 1 & Factor 2 & Factor 3 \\
\hline History of stroke & 0.70 & -0.04 & 0.03 \\
\hline Stepwise progression & 0.72 & 0.05 & -0.07 \\
\hline Focal neurological symptoms & 0.75 & 0.20 & 0.00 \\
\hline Abrupt onset & 0.75 & 0.02 & -0.03 \\
\hline Focal neurological signs & 0.58 & 0.07 & 0.14 \\
\hline Evidence of associated atherosclerosis & 0.49 & -0.12 & 0.05 \\
\hline History of hypertension & 0.47 & -0.06 & 0.07 \\
\hline Fluctuating course & 0.52 & -0.21 & -0.07 \\
\hline Depression & 0.19 & 0.19 & -0.18 \\
\hline Somatic complaints & 0.16 & -0.04 & -0.09 \\
\hline Relative preservation of personality & 0.12 & -0.47 & -0.13 \\
\hline Slow progression & -0.81 & -0.14 & 0.11 \\
\hline Echolalia, late mutism, amimia (during the course) & -0.13 & 0.58 & -0.05 \\
\hline Early signs of disinhibition & 0.00 & 0.68 & -0.17 \\
\hline Early loss of insight & -0.25 & 0.40 & 0.16 \\
\hline Progressive reduction of speech & 0.06 & 0.46 & 0.00 \\
\hline Klüver-Bucy syndrome (hyperorality, hypersexuality, utilization behaviour) & -0.09 & 0.49 & 0.03 \\
\hline Stereotypy of speech & -0.11 & 0.41 & -0.11 \\
\hline Logorrhea (voluble speech) & -0.13 & 0.27 & 0.11 \\
\hline Irritability, dysphoria & 0.10 & 0.26 & 0.27 \\
\hline Dyspraxia, dysphasia, dysgnosia (all symptoms present to some extent) & -0.30 & -0.58 & 0.52 \\
\hline Epileptic seizure of late onset & 0.00 & 0.03 & 0.60 \\
\hline Increased muscular tension & 0.00 & -0.09 & 0.58 \\
\hline Myoclonic twitchings & -0.09 & -0.04 & 0.63 \\
\hline Early spatial disorientation & -0.32 & -0.72 & 0.31 \\
\hline Early amnesia for remote events & -0.43 & -0.67 & 0.32 \\
\hline Confabulation, spontaneous & -0.03 & -0.06 & 0.35 \\
\hline Logoclonia (stuttering-like speech disturbance) & -0.13 & 0.01 & 0.41 \\
\hline Nocturnal confusion & 0.03 & -0.17 & 0.39 \\
\hline Emotional incontinence & 0.23 & 0.08 & 0.36 \\
\hline Eigenvalue & 5.2 & 3.7 & 1.9 \\
\hline Variance $\%$ & 17,3 & 12,2 & 6,4 \\
\hline
\end{tabular}


TABLE 4: A four-factor analysis of 30 clinical items scored in 190 patients with neuropathological diagnosis of VaD, AD, mixed AD/VaD and FTD. Factor loadings $\geq 0.25$ are in bold. Factor loadings $\leq-0.24$ are set in italic.

\begin{tabular}{|c|c|c|c|c|}
\hline & $\begin{array}{l}\text { Factor } 1 \\
\text { Vascular }\end{array}$ & $\begin{array}{l}\text { Factor } 2 \\
\text { Frontal }\end{array}$ & $\begin{array}{l}\text { Factor } 3 \\
\text { Alz.type }\end{array}$ & $\begin{array}{l}\text { Factor } 4 \\
\text { Mood }\end{array}$ \\
\hline History of stroke & 0.71 & -0.04 & 0.02 & -0.03 \\
\hline Stepwise progression & 0.67 & 0.03 & -0.07 & 0.14 \\
\hline Focal neurological symptoms & 0.74 & 0.20 & 0.00 & 0.01 \\
\hline Abrupt onset & 0.75 & 0.02 & -0.04 & -0.04 \\
\hline Focal neurological signs & 0.64 & 0.09 & 0.12 & -0.17 \\
\hline Evidence of associated atherosclerosis & 0.49 & -0.12 & 0.04 & 0.00 \\
\hline History of hypertension & 0.48 & -0.06 & 0.06 & -0.03 \\
\hline Fluctuating course & 0.49 & -0.22 & -0.07 & 0.08 \\
\hline Depression & 0.04 & 0.11 & -0.11 & 0.72 \\
\hline Somatic complaints & 0.01 & -0.10 & -0.05 & 0.55 \\
\hline Relative preservation of personality & 0.04 & -0.49 & -0.13 & 0.21 \\
\hline Slow progression & -0.79 & -0.13 & 0.11 & -0.04 \\
\hline Echolalia, late mutism, amimia (during the course) & -0.11 & 0.58 & -0.03 & -0.04 \\
\hline Early signs of disinhibition & 0.00 & 0.68 & -0.14 & -0.01 \\
\hline Early loss of insight & -0.18 & 0.42 & 0.16 & -0.18 \\
\hline Progressive reduction of speech & 0.01 & 0.44 & 0.04 & 0.25 \\
\hline Klüver-Bucy syndrome (hyperorality, hypersexuality, utilization behaviour) & 0.13 & 0.48 & 0.06 & 0.16 \\
\hline Stereotypy of speech & -0.07 & 0.42 & -0.10 & -0.09 \\
\hline Logorrhea (voluble speech) & -0.02 & 0.30 & 0.10 & -0.33 \\
\hline Irritability, dysphoria & 0.00 & 0.22 & 0.31 & 0.40 \\
\hline Dyspraxia, dysphasia, dysgnosia (all symptoms present to some extent) & -0.23 & -0.56 & 0.48 & -0.17 \\
\hline Epileptic seizure of late onset & -0.00 & 0.03 & 0.62 & 0.11 \\
\hline Increased muscular tension & 0.01 & -0.09 & 0.59 & 0.10 \\
\hline Myoclonic twitchings & 0.00 & 0.00 & 0.62 & -0.19 \\
\hline Early spatial disorientation & -0.31 & -0.71 & 0.28 & -0.04 \\
\hline Early amnesia for remote events & -0.38 & -0.65 & 0.29 & -0.14 \\
\hline Confabulation, spontanteous & 0.05 & -0.03 & 0.34 & -0.21 \\
\hline Logoclonia (stuttering-like speech disturbance) & -0.10 & 0.02 & 0.41 & -0.04 \\
\hline Nocturnal confusion & 0.02 & -0.17 & 0.39 & 0.06 \\
\hline Emotional incontinence & 0.12 & 0.05 & 0.39 & 0.42 \\
\hline Eigenvalue & 5.2 & 3.7 & 1.9 & 1.6 \\
\hline Variance $\%$ & 17.3 & 12.2 & 6.4 & 5.3 \\
\hline
\end{tabular}


TABLE 5: Rating scales for differential diagnosis of dementia.

\begin{tabular}{|c|c|c|c|c|c|}
\hline \multicolumn{2}{|l|}{ Alzheimer's disease scale } & \multicolumn{2}{|l|}{ Frontotemporal dementia scale } & \multicolumn{2}{|l|}{ Hachinski Ischemic Score, HIS } \\
\hline Symptom/item & Score & Symptom/item & Score & Symptom/item & Score \\
\hline Slow progression & 1 & Slow progression & 1 & Abrupt onset & 2 \\
\hline Early loss of insight & 1 & Early loss of insight & 2 & Stepwise progression & 1 \\
\hline Early amnesia for remote events & 2 & Early signs of disinhibition & 2 & Fluctuating course & 2 \\
\hline Early spatial disorientation & & Irritability, dysphoria & 1 & Nocturnal confusion & 1 \\
\hline (impaired sense of locality) & 2 & Confabulation spontaneous & 1 & Relative preservation of personality & 1 \\
\hline Dyspraxia, dysphasia, dysgnosia, (all & & Logorrhea, (voluble speech) & 1 & Depression & 1 \\
\hline symptoms present to some extent) & 2 & Progressive reduction of speech & 1 & Somatic complaints & 1 \\
\hline Logoclonia, (stuttering-like speech & & Stereotypy of speech & 1 & Emotional incontinence & 1 \\
\hline disturbance) & 2 & Echolalia, late mutism, amimia, (at & & History of hypertension & 1 \\
\hline Logorrhoea, (voluble speech) & 1 & least two of three symptoms during the & & History of strokes & 2 \\
\hline Progressive reduction of speech & 1 & course) & 2 & Evidence of associated & \\
\hline Epileptic seizure of late onset & 1 & Klüver-Bucy syndrome, & & atherosclerosis & 1 \\
\hline Increased muscular tension & 2 & (hyperorality, hypersexuality & & Focal neurological symptoms & 2 \\
\hline Myoclonic twitchings & 1 & utilization behaviour) & 1 & Focal neurological signs & 2 \\
\hline \multicolumn{6}{|l|}{ Klüver-Bucy syndrome, (hyperorality, } \\
\hline hypersexuality, utilization behaviour) & 1 & & & & \\
\hline Total score & & Total score & & Total score & \\
\hline Max score 17 & & Max score 13 & & Max score 18 & \\
\hline
\end{tabular}

speech" (0.25). Together these five items highlight the clinical importance of a symptom pattern described by emotional feelings and expressions (Figure 1).

Figure 1 shows the mean number of patients (in percent) within each diagnostic group, scoring on each individual item within the respective factor. The vascular, frontal, and Alzheimer type factors showed specific relationship to the respective NP diagnoses, while the symptoms of the mood factor were found in all four NP groups.

\section{Discussion}

In an earlier publication from our prospective longitudinal study of dementia conditions, three diagnostic rating scales with thirty clinical items were validated against NP diagnoses of dementia. The results showed satisfactory specificity and sensitivity of the rating scales for diagnosis of $\mathrm{AD}$, FTD, $\mathrm{VaD}$, and mixed $\mathrm{AD} / \mathrm{VaD}$. The aim of the present study was to further elucidate the structure of the rating scales by factor analysis of the clinical items that were used in the diagnostic process. The scoring was based on direct observations as well as on information from the patient and other informants. This information is also crucial for estimation of the patients' premorbid personality, emotional behaviour, social competence, cognitive profile, education, and clinical changes over time. There are limitations but

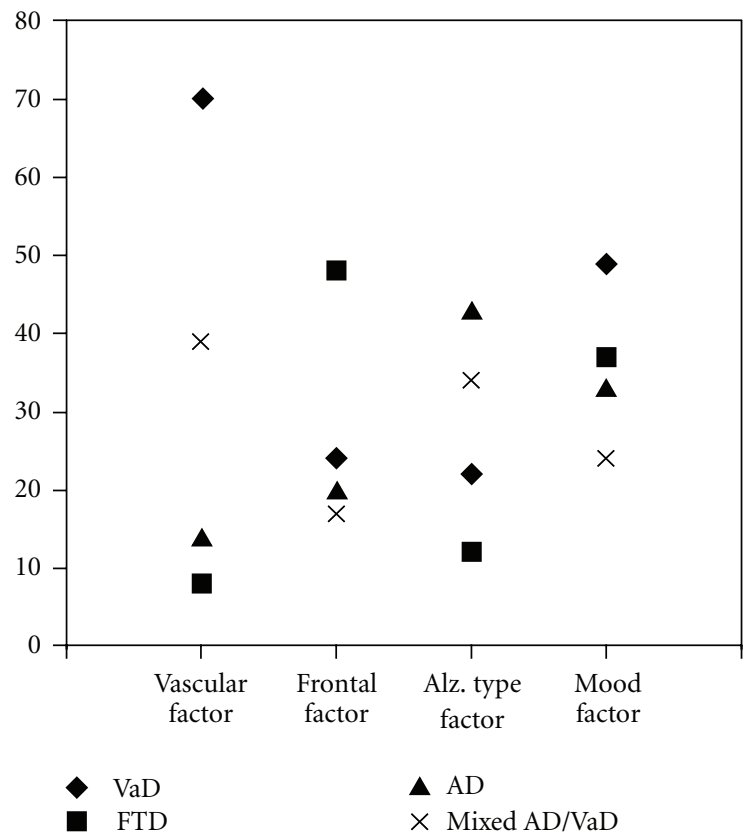

FIgURE 1: The X-axis depicts the individual factors obtained in the 4 -factor analysis presented in Table 4 . The points in the graph show the mean number of patients (in percent) within each diagnostic group, scoring on each individual item within the respective factor. 


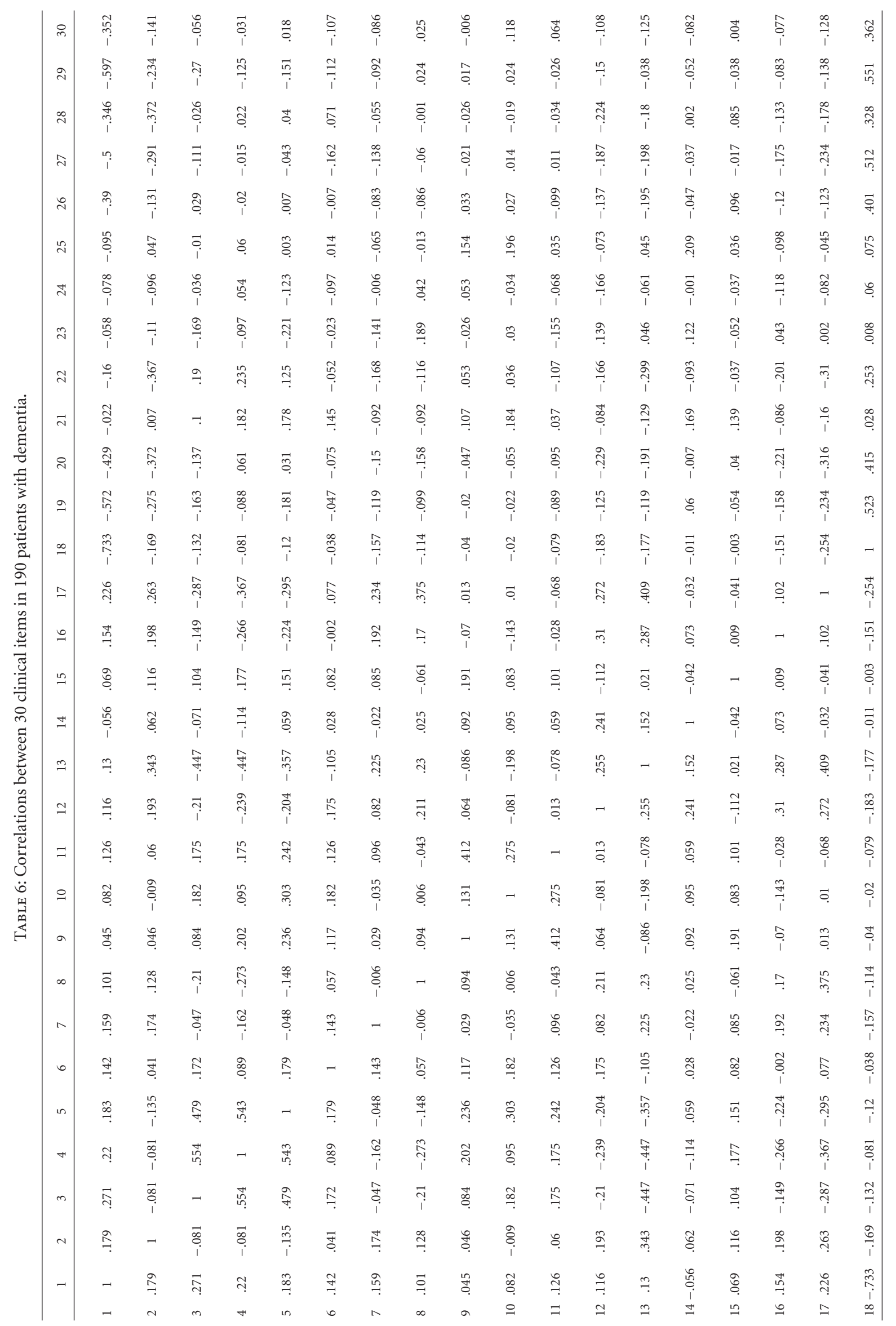




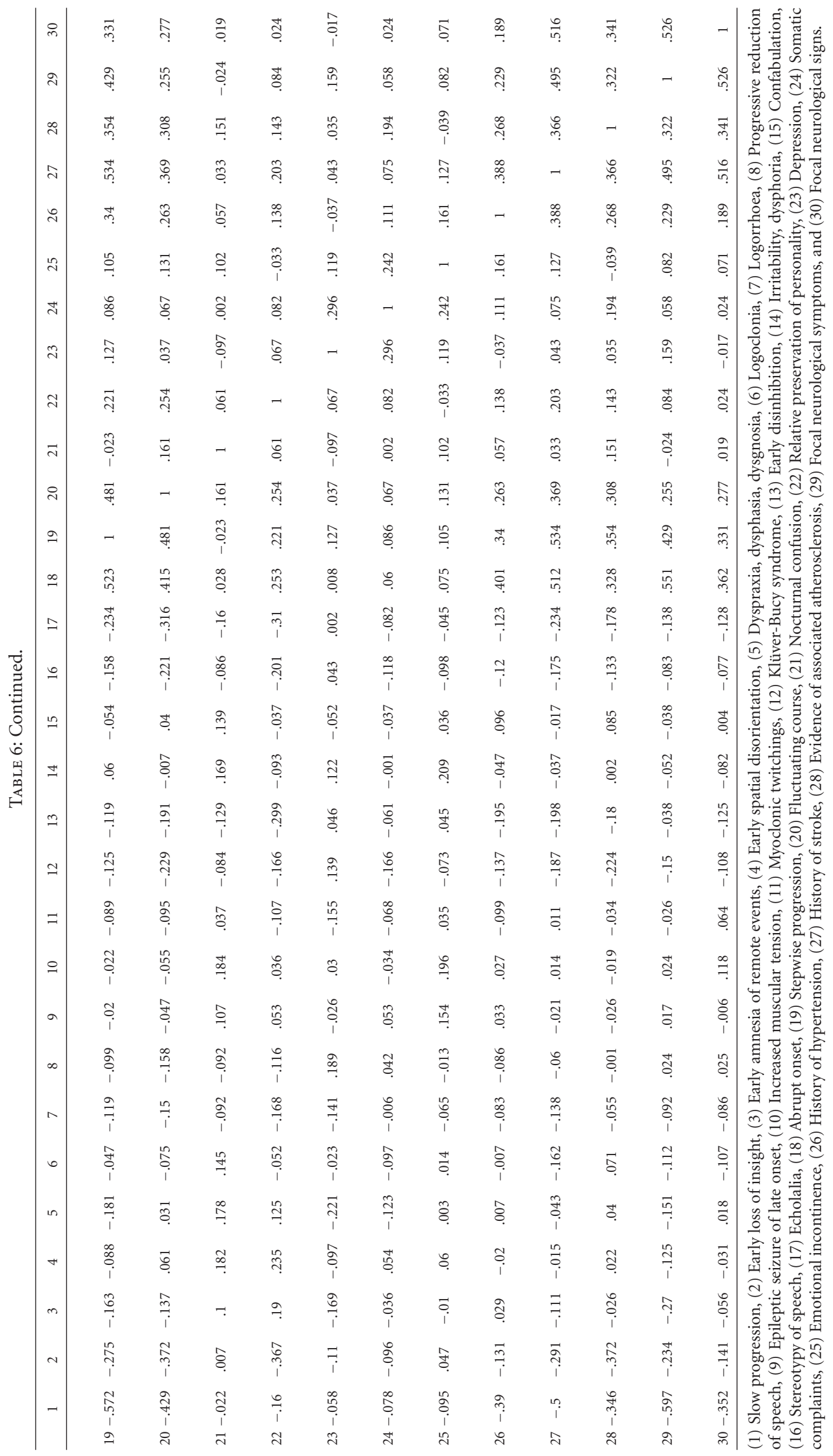


also advantages of the long-term design of this study. There might be certain difficulties to standardize the diagnostic process, both the clinical and the histopathological aspects. In fifteen items, the evaluation was based on the patient's medical history as well as on clinical observations. Twelve items relied on history mainly, and for three items (increased muscular tension, evidence of associated arteriosclerosis, and focal neurological signs) the scoring was almost exclusively based on observations.

An additional limitation to be considered is the sample size. The 190 cases were considered representative of patients referred for clinical examination and diagnosis of dementia disease [11]. The mean age at onset was fairly low probably due to the comparatively large number of FTD cases. Moreover, there was a wide range of the disease duration compared to other studies of postmortem verified dementia. During the time span of the NP examinations in the present study, the procedures and the classification of dementia have developed and changed. The advent of immunohistochemistry in the 1980-90 supplemented the basic neuropathological observations made during the 20 years antedating the mentioned histotechnical advances. Basically these innovations confirmed the originally observed changes rather than adding new features. Still, however, AD, VaD, mixed $\mathrm{AD} / \mathrm{VaD}$, and FTD have been the predominant $\mathrm{NP}$ diagnoses similar to those in other large studies [23]. Patients with $\mathrm{AD}$ pathology probably include cases with additional histopathological presence of dementia with Lewy bodies.

The clinical dimensions were attained and studied with conventional factor analysis. We are contented with the first three factors with high eigenvalues and meaningful clinical constructs based on unique items and "significant" factor loadings. Factor 1 with a strong similarity to the original HIS contained items describing risk factors, clinical course, symptoms, and signs associated with cerebrovascular disease [24]. Factor 2 presented a cluster of clinical features associated with brain dysfunction predominantly involving frontal and frontotemporal brain areas. It has a striking similarity to the consensus on clinical criteria for FTD [25] and frontotemporal lobar degeneration (FTLD) [26]. Finally, the third factor contained cognitive, executive, and neurological symptoms related to hippocampal, temporoparietal, and subcortical structures often involved in AD. Although none of these symptoms are unique for AD, they may strongly contribute to the diagnostic reliability, when appearing in a specific constellation. The factor analyses strongly support the construct validity of the three diagnostic rating scales. Finally the factor analysis also revealed a new symptom cluster characterised by perception and expression of emotions. The rating scales and the factor solutions are recommended for clinical as well as research centre settings.

\section{Acknowledgments}

The authors thank Helena Andersson for technical assistance and Fredrik Nilsson at the RSKC for statistical assistance. This work was supported by the Trolle-Wachtmeister Foun- dation for Medical research, The Swedish Research Council (Grant no. 03950-33A), The Swedish Alzheimer Foundation, The Sjöbring Foundation, and ALF (Region of Skane).

\section{References}

[1] L. Gustafson and U. Passant, "Clinical pathological correlates," in Cerebrovascular Disease, Cognitive Impairment and Dementia, J. O’Brien, D. Ames, L. Gustafson, M. Folstein, and E. Chiu, Eds., pp. 197-210, Martin Dunitz, London, UK, 2004.

[2] L. Gustafson and B. Hagberg, "Dementia with onset in the presenile period. A cross-sectional study," Acta Psychiatrica Scandinavica, Supplement, vol. 257, pp. 3-71, 1975.

[3] L. Gustafson and J. Risberg, "Regional cerebral blood flow related to psychiatric symptoms in dementia with onset in the presenile period," Acta Psychiatrica Scandinavica, vol. 50, no. 5, pp. 516-538, 1974.

[4] J. E. Overall and S. A. Beller, "The brief psychiatric rating scale (BPRS) in geropsychiatric research: I. Factor structure on an inpatient unit," Journals of Gerontology, vol. 39, no. 2, pp. 187193, 1984.

[5] M. Petrovic, C. Hurt, D. Collins et al., "Clustering of behavioural and psychological symptoms in dementia (BPSD): a european alzheimer's disease consortium (EADC) study," Acta Clinica Belgica, vol. 62, no. 6, pp. 426-432, 2007.

[6] G. B. Frisoni, L. Rozzini, A. Gozzetti et al., "Behavioral syndromes in Alzheimer's disease: description and correlates," Dementia and Geriatric Cognitive Disorders, vol. 10, no. 2, pp. 130-138, 1999.

[7] P. Aalten, F. R. J. Verhey, M. Boziki et al., "Consistency of neuropsychiatric syndromes across dementias: results from the European Alzheimer Disease Consortium-part II," Dementia and Geriatric Cognitive Disorders, vol. 25, no. 1, pp. 1-8, 2008.

[8] K. B. Björkelund, S. Larsson, L. Gustafson, and E. Andersson, "The Organic Brain Syndrome (OBS) scale: a systematic review," International Journal of Geriatric Psychiatry, vol. 21, no. 3, pp. 210-222, 2006.

[9] L. Gustafson and L. Nilsson, "Differential diagnosis of presenile dementia on clinical grounds," Acta Psychiatrica Scandinavica, vol. 65, no. 3, pp. 194-209, 1982.

[10] V. C. Hachinski, L. D. Iliff, and E. Zilhka, "Cerebral blood flow in dementia," Archives of Neurology, vol. 32, no. 9, pp. 632-637, 1975.

[11] L. Gustafson, E. Englund, H. Brunnström et al., "The accuracy of short clinical rating scales in neuropathologically diagnosed dementia," American Journal of Geriatric Psychiatry, vol. 18, no. 9, pp. 810-820, 2010.

[12] American Psychiatric Association, DSM-III-R, Diagnostic and Statistical Manual of Mental Disorders, APA, Washington, DC, USA, 1987.

[13] World Health Organization, ICD-10, World Health Organization Tenth Revision of the International Classification of Diseases, WHO, Geneva, Switzerland, 1992.

[14] P. Horst, Factor Analysis of Data Matrices, Holt, Rienhart and Winston, New York, NY, USA, 1965.

[15] I. McDowell and C. Newell, Measuring Health: A Guide to Rating Scales and Questionnaires, Oxford University Press, New York, NY, USA, 1996.

[16] F. N. Kerlinger, Foundations of Behavioral Research, Holt, Rinehart and Winston, New York, NY, USA, 1967.

[17] J. C. Nunnally, Psychometric Theory, McGraw-Hill, New York, NY, USA, 2nd edition, 1978. 
[18] R. L. Gorsuch, Factor Analysis, Erlbaum, Hillsdale, NJ, USA, 2nd edition, 1983.

[19] B. G. Tabachnick and L. S. Fidell, Using Multivariate Statistics, Harper \& Row, New York, NY, USA, 3rd edition, 1996.

[20] R. Cudeck and L. L. O’Dell, "Applications of standard error estimates in unrestricted factor analysis: significance tests for factor loadings and correlations," Psychological Bulletin, vol. 115, no. 3, pp. 475-487, 1994.

[21] L. Hatcher, A Step-by-Step Approach Using hte SAS ${ }^{\circledR}$ System for Factor Analysis and Structural Equation Modeling, SAS Institute, Cary, NC, USA, 1994.

[22] G. Hutcheson and N. Sofroniou, The Multivariate Social Scientist: Introductory Statistics Using Generalised Linear Models, Sage, Thousand Oaks, Calif, USA, 1999.

[23] H. Brunnstrom, L. Gustafson, U. Passant, and E. Englund, "Prevalence of dementia subtypes: a 30-year retrospective survey of neuropathological reports," Archives of Gerontology and Geriatrics, vol. 49, no. 1, pp. 146-149, 2009.

[24] U. Andin, L. Gustafson, A. Brun, and U. Passant, "Clinical manifestations in neuropathologically defined subgroups of vascular dementia," International Journal of Geriatric Psychiatry, vol. 21, no. 7, pp. 688-697, 2006.

[25] A. Brun, B. Englund, L. Gustafson et al., "Clinical and neuropathological criteria for frontotemporal dementia," Journal of Neurology Neurosurgery and Psychiatry, vol. 57, no. 4, pp. 416-418, 1994.

[26] D. Neary, J. S. Snowden, L. Gustafson et al., "Frontotemporal lobar degeneration: a consensus on clinical diagnostic criteria," Neurology, vol. 51, no. 6, pp. 1546-1554, 1998. 


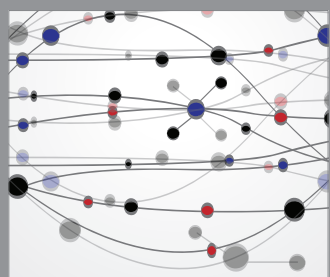

The Scientific World Journal
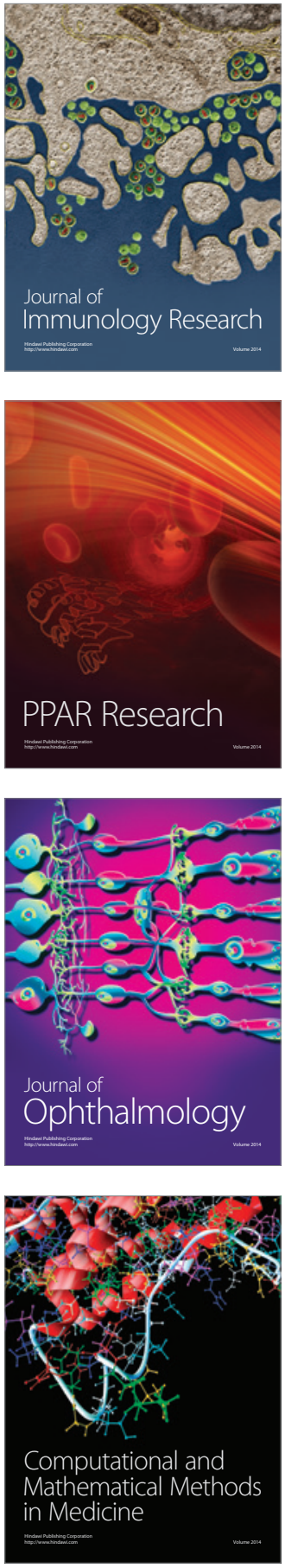

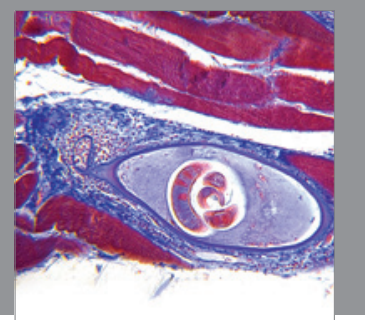

Gastroenterology

Research and Practice
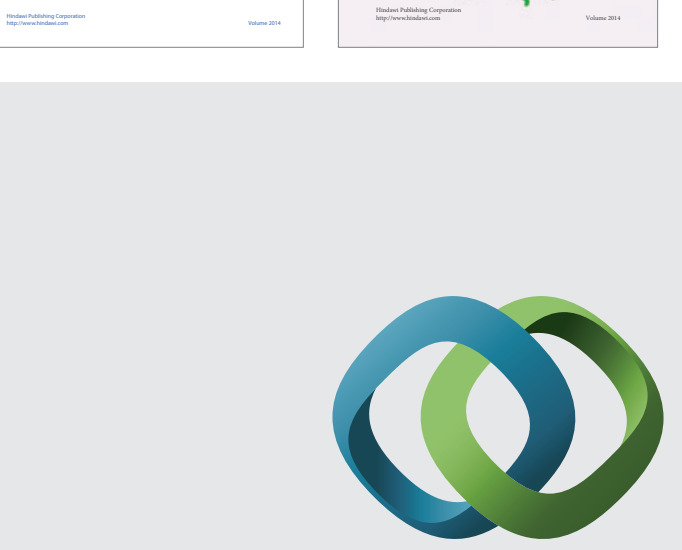

\section{Hindawi}

Submit your manuscripts at

http://www.hindawi.com
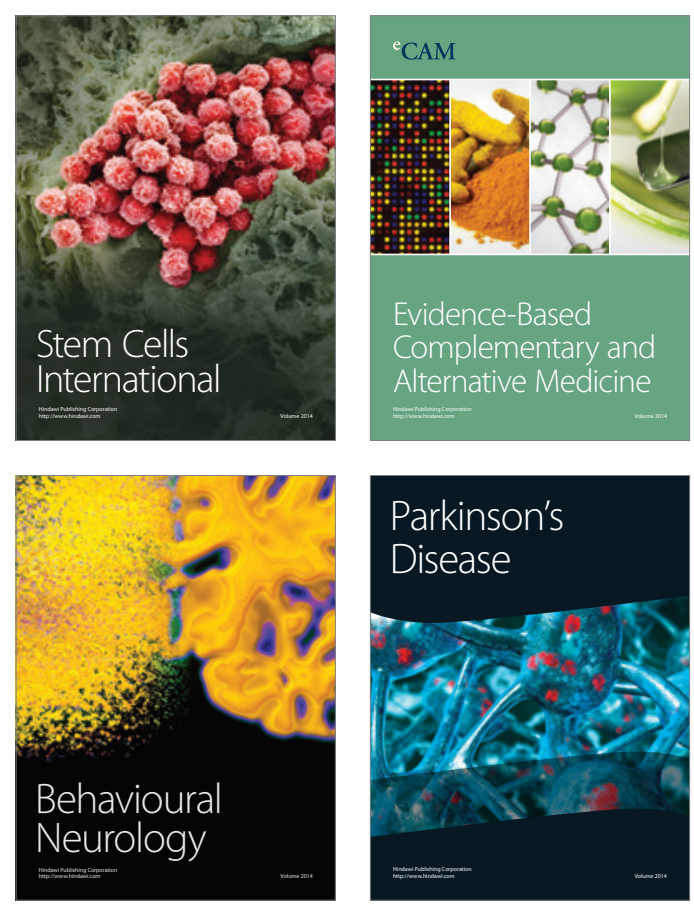

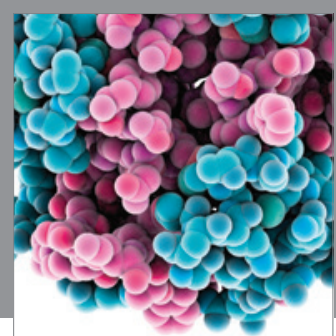

Journal of
Diabetes Research

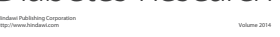

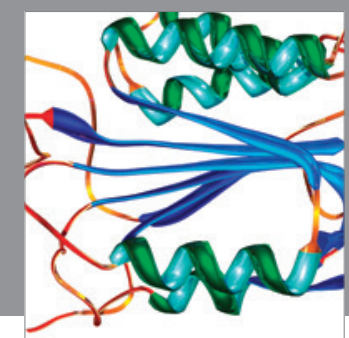

Disease Markers
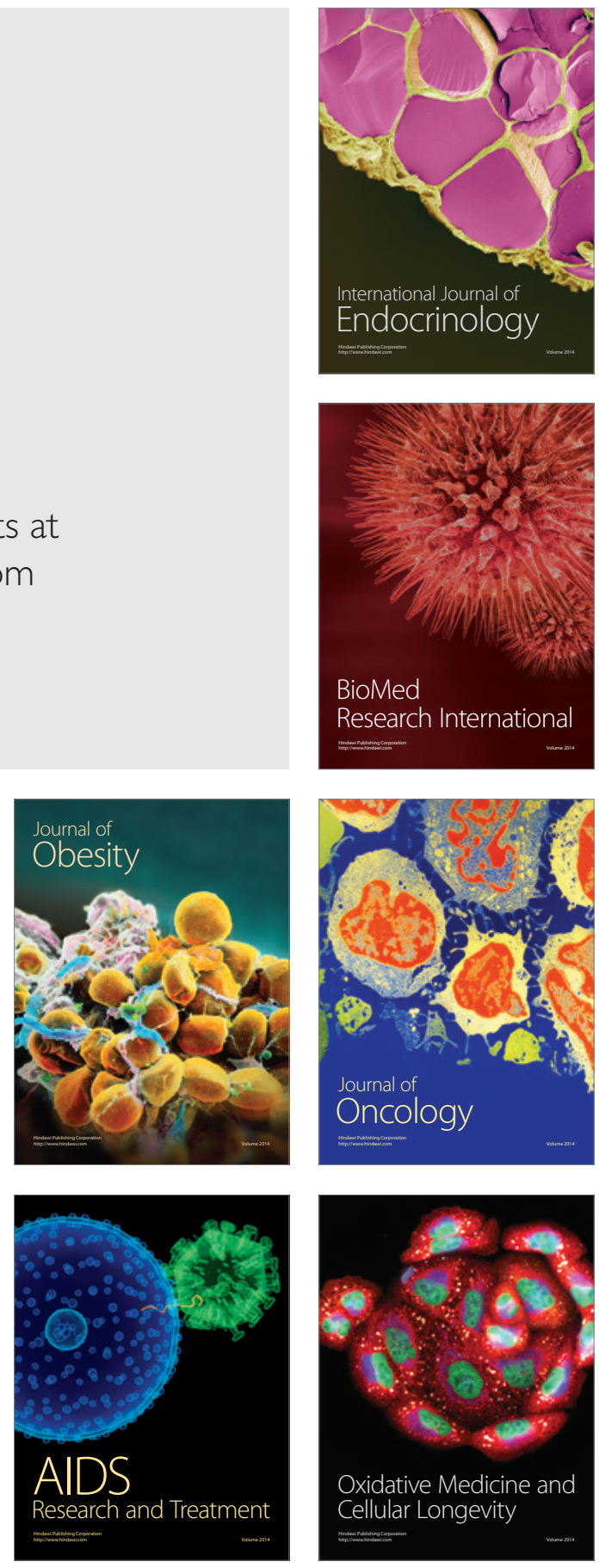